\title{
Gastroesophageal reflux disease symptoms in
Greek general population: prevalence and risk factors
}

\author{
Nikolaos Spantideas' \\ Eirini Drosou' \\ Anastasia Bougea ${ }^{2}$ \\ Dimitrios Assimakopoulos ${ }^{3}$
}

'Athens Speech Language and Swallowing Institute, Glyfada, Athens, Greece; ${ }^{2}$ Athens Speech Language and Swallowing Institute, Agios Dimitrios, Athens, Greece; ${ }^{3}$ Department of Otorhinolaryngology, Medical School of loannina University, University Hospital of loannina, loannina, Greece

Correspondence: Nikolaos Spantideas Athens Speech Language and Swallowing Institute, I0 Lontou Street, Glyfada,

Athens 16675, Greece

Tel +30 6944526007

Fax +30 2I 096I 4420

Email spandideas@gmail.com
This article was published in the following Dove Press journal:

Clinical and Experimental Gastroenterology

21 June 2016

Number of times this article has been viewed

Background and aims: Population-based data regarding the prevalence of gastroesophageal reflux disease (GERD) in Greece are very poor. This study estimated the prevalence of GERD symptoms and their risk factors in the Greek adult population.

Methods: A self-administered questionnaire was answered by a randomly selected population of 340 subjects. The question regarding "heartburn, chest pain, indigestion, or stomach acid coming up" as included in the Reflux Symptom Index was used for prevalence assessment.

Results: The monthly prevalence of GERD symptoms was found to be $52.0 \%$ in the Greek general population, with no statistically significant difference between the two sexes $(P>0.05)$. The age group of 65-79 years showed a higher prevalence rate of GERD. Symptom severity was found to be mild $(59.3 \%)$ or moderate $(27.1 \%)$. The number of cigarettes smoked daily (but not smoking duration) as well as the number of alcoholic drinks consumed daily (but not the duration of alcohol drinking) were found to be related to GERD symptoms. No reported concomitant disease or medication was found to be related with GERD symptoms.

Conclusion: The prevalence of GERD symptoms in the Greek general population was found to be $52.0 \%$. Tobacco smoking and alcohol drinking but not concomitant disease or medications were found to be related with GERD symptoms.

Keywords: gastroesophageal reflux, reflux, epidemiologic study, risk factors

\section{Introduction}

Gastroesophageal reflux disease (GERD) is a prevalent, chronic, and relapsing gastrointestinal disorder in which gastric contents reflux into the esophagus. There is a lack of consensus as to the definition of GERD. The Montreal definition of GERD published in 2006 is the most acceptable one and defines GERD as "troublesome symptoms (including heartburn, acid regurgitation, and epigastric pain) and complications". ${ }^{1}$

The range of GERD prevalence is estimated to be $18.1 \%-27.8 \%$ in North America, 8.8\%-25.9\% in Europe, $2.5 \%-7.8 \%$ in East Asia, $8.7 \%-33.1 \%$ in the Middle East, $11.6 \%$ in Australia, and $23.0 \%$ in South America. ${ }^{1}$ The prevalence of symptoms of GERD in the general population ranges from $26 \%$ to $60 \% .^{2-6}$ It seems that the prevalence of GERD in Western communities has increased in recent decades. ${ }^{7,8}$

Contrary to what is observed in most European countries, data concerning the prevalence of GERD in the Greek population are very poor as there is only one study regarding the prevalence of upper and lower gastrointestinal symptoms in the Greek urban general population. ${ }^{9}$ 
The diagnosis of GERD is made using a combination of symptom presentations, objective testing with endoscopy, ambulatory esophageal $\mathrm{pH}$ monitoring, and response to antisecretory therapy. Classic symptoms of burning in the chest, with sour or bitter taste, and acid regurgitation have been shown to correctly identify GERD with a sensitivity of $89 \%$ and specificity of $94 \% .{ }^{10}$

Symptom questionnaires are based on symptoms reported by the patient, and these symptoms can be formally assessed using validated questionnaires. Among different symptoms, heartburn and regurgitation are the most reliable for making a presumptive GERD diagnosis. Symptom-based questionnaires are the most widely used method for detecting the GERD prevalence, especially in large-scale epidemiologic studies.

Several questionnaires for GERD diagnosis have been developed and validated. These include the Reflux Disease Questionnaire, ${ }^{11}$ the frequency scale for symptoms of Gastroesophageal Reflux Disease, ${ }^{12}$ and the Re-Quest Questionnaire. ${ }^{13}$ Symptom evaluation is also useful for assessing treatment efficacy.

The Reflux Symptom Index (RSI) introduced by Belafsky et $\mathrm{a}^{14}$ is a self-administered nine-item questionnaire designed to assess various symptoms related to laryngopharyngeal reflux (LPR). Each item is rated on a scale from 0 (no problem) to 5 (severe problem), with a maximum total score of 45 , indicating the most severe symptoms. A key question of the RSI regards the experience of "heartburn, chest pain, indigestion, or stomach acid coming up" during the previous month. These are the main symptoms included in all questionnaires developed for the diagnosis of GERD. ${ }^{14-16}$ In addition, RSI can give information not only about the prevalence of the included items in the questionnaire but also about their severity.

Since the introduction of RSI, many studies have been conducted mainly to detect LPR prevalence or to monitor LPR therapy, but no further analysis of the prevalence of each item included in the questionnaire has been presented.

The primary aim of this study was to assess the prevalence of GERD symptoms in the general adult Greek population using the question regarding "heartburn, chest pain, indigestion, or stomach acid coming up" included in the RSI, and to detect risk factors associated with GERD symptoms. The present study is the first that assesses the prevalence of GERD symptoms based on the presence of symptoms included in the RSI during the last month.

\section{Materials and methods}

The study was carried out in the general Greek population during the period from September to November 2013.
A random sample $(\mathrm{n}=1,000)$ of adults living in Athens (500 people) and in rural Greek areas (500 people) was initially approached through an "alert" telephone conversation. During the communication, the scope of the study was explained, and permission to send the questionnaire to the subjects' address was verbally obtained. The random selection of the participants was made through the telephone catalog for Athens city, and telephone catalogs of randomly selected rural areas using a table of random numbers generated for the study. Five different investigators performed the calls 10 days before sending the questionnaire. Of the 1,000 subjects approached, 450 agreed to participate and provided their personal details (name and address). Only one person per family was required to fill in the questionnaire. In the envelope that was sent to the participants, a more detailed explanation for the scope of the study, detailed instructions for filling out the questionnaires, an informed consent form, and a prepaid envelope were included, so that subjects could easily send back the filled-in questionnaire as well as the signed informed consent at no cost for them. Three hundred and fifty individuals returned the questionnaires (189 or 54\% from the Athens area, and 161 or $46 \%$ from rural areas).

Data related to GERD symptoms were gathered through a questionnaire in which information about demographic data of the participants, concomitant diseases, concurrent medication, as well as the RSI questions were included. The RSI questionnaire has been translated into Greek and has been validated in the Greek population. ${ }^{15}$

Inclusion criterion for our study was subjects' aged $\geq 18$ years, because the main scope of our study was to assess the prevalence of GERD symptoms in the general adult population. Subjects with preexisting gastroesophageal reflux and those taking antireflux medications were also included in the study.

Exclusion criteria for participation in the study were patients diagnosed with gastrointestinal malignancies and peptic or duodenal ulcers.

For the purpose of this study, the prevalence of GERD symptoms was based on the participants' response to the question regarding "heartburn, chest pain, indigestion, or stomach acid coming up" during last month.

The study protocol was approved by the Scientific Committee and Review Board of Athens Speech Language and Swallowing Institute and conforms to the ethical guidelines of the 1975 Declaration of Helsinki (6th revision, 2008) as reflected in a priori approval by the institution's human research committee.

Written informed consent was obtained from all participants prior to inclusion in the study. 


\section{Statistical methodology}

Statistical tests were performed using the IBM SPSS Statistics 20 software (IBM Corporation, Armonk, NY, USA).

Descriptive statistics were used to summarize data for the subset of the population with GERD symptoms. Chi-square tests were used to compare the distribution of categorical variables among patients with GERD symptoms compared to those without. Student's $t$-test was used to compare continuous variables between patients with GERD symptoms and the rest of the population. A $P$-value of $<0.05$ was used to determine statistical significance.

Variables of the analysis were as follows: demographic parameters, smoking and drinking habits, health background (concomitant diseases), concomitant medication, and the RSI.

\section{Results}

Four hundred and fifty randomly selected subjects accepted the invitation to participate in the study. Three hundred and fifty subjects (response rate $77.8 \%$ ) returned the completed questionnaire. In ten of 350 returned questionnaires, critical information, such as sex and age, were lacking, so finally 340 (183 male and 157 female) questionnaires were appropriate for statistical analysis.

The mean age of participants was 46.86 ( $\mathrm{SD} \pm 14.54$ years). Most participants belonged to the age group of 35-49 years (131 subjects), whereas the age groups of older than 80 years and younger than 20 years were poorly represented (three subjects older than 80 years and two subjects younger than 20 years). Participants' age and sex are presented in Table 1.

One hundred and seventy-seven subjects or $52.0 \%$ of the participants reported GERD-attributed symptoms (heartburn, chest pain, indigestion, or stomach acid coming up). One hundred and three were male (58.2\%) and 74 were female $(41.8 \%)$, and there was no statistically significant difference in reporting GERD symptoms between the two

Table I Participant's age and sex

\begin{tabular}{llll}
\hline Variable & Group & N & $\%$ \\
\hline Sex & Female (F) & I57 & 46.2 \\
& Male (M) & I 83 & 53.8 \\
& Total & 340 & 100.0 \\
Age distribution (mean age: & $<20$ & $2(2 \mathrm{M})$ & 0.6 \\
46.86, SD \pm |4.54 years) & $20-34$ & 7 I (29M +42F) & 20.9 \\
& $35-49$ & I3I (78M +53F) & 38.5 \\
& $50-64$ & $88(43 \mathrm{M}+45 \mathrm{~F})$ & 25.9 \\
& $65-79$ & $45(30 \mathrm{M}+\mathrm{ISF})$ & 13.2 \\
& $\geq 80$ & $3(\mathrm{IM}+2 \mathrm{~F})$ & 0.9 \\
& Total & 340 & 100.0 \\
\hline
\end{tabular}

sexes $(P=0.086)$. Also, there was no statistically significant difference in GERD symptoms reporting between urban and rural dwellers $(P=0.094)$.

GERD symptoms were more frequently reported in the age group of 65-79 years (64.4\%) followed by the age group of 50-64 years $(56.8 \%)$ (Table 2$)$.

The severity of GERD symptoms was similarly distributed between the two sexes (Table 3).

One hundred and five subjects (59.3\%) of 177 with GERD symptoms reported mild symptoms (severity scores 1 and 2), 48 subjects or $27.1 \%$ reported moderate symptoms (severity score 3 ), and 24 subjects or $13.5 \%$ reported severe symptoms (severity score 4 and 5) (Table 4).

One hundred and seventy-four $(51.2 \%)$ of the total participants were tobacco smokers, with a mean number of cigarettes smoked daily of 20.5 and mean duration of smoking 18.23 ( $\mathrm{SD} \pm 8.6$ ) years for males and $17.02(\mathrm{SD} \pm 8.0)$

Table 2 Distribution of gastroesophageal symptoms (heartburn, chest pain, indigestion, or stomach acid coming up) according to age group

\begin{tabular}{|c|c|c|c|c|c|c|c|}
\hline \multirow[t]{3}{*}{ Age distribution } & \multicolumn{6}{|c|}{$\begin{array}{l}\text { Heartburn, chest pain, indigestion, } \\
\text { or stomach acid coming up, } n\end{array}$} & \multirow[t]{3}{*}{$\begin{array}{l}\text { Total, } \\
\mathbf{N}\end{array}$} \\
\hline & \multicolumn{6}{|c|}{ Score } & \\
\hline & 0 & I & 2 & 3 & 4 & 5 & \\
\hline \multicolumn{8}{|l|}{ Age (grouped), years } \\
\hline$<20$ & 2 & 0 & 0 & 0 & 0 & 0 & 2 \\
\hline $20-34$ & 39 & 10 & 10 & 7 & 2 & 3 & 71 \\
\hline $35-49$ & 66 & 24 & 17 & 16 & 5 & 3 & 131 \\
\hline $50-64$ & 38 & 12 & 15 & 16 & 5 & 2 & 88 \\
\hline $65-79$ & 16 & 6 & 10 & 9 & 3 & I & 45 \\
\hline$\geq 80$ & 2 & 0 & 1 & 0 & 0 & 0 & 3 \\
\hline Total & 163 & 52 & 53 & 48 & 15 & 9 & 340 \\
\hline
\end{tabular}

Note: Scored from 0 (no problem) to 5 (severe problem).

Table 3 Severity of gastroesophageal symptoms (heartburn, chest pain, indigestion, or stomach acid coming up) according to sex

\begin{tabular}{|c|c|c|c|c|c|c|c|}
\hline \multirow[t]{3}{*}{ Sex } & \multicolumn{6}{|c|}{$\begin{array}{l}\text { Heartburn, chest pain, indigestion, or } \\
\text { stomach acid coming up }\end{array}$} & \multirow[t]{3}{*}{ Total } \\
\hline & \multicolumn{6}{|c|}{ Score } & \\
\hline & 0 & $I$ & 2 & 3 & 4 & 5 & \\
\hline \multicolumn{8}{|l|}{ Female } \\
\hline Number & 83 & 14 & 27 & 24 & 6 & 3 & 157 \\
\hline$\%$ of total & 24.4 & 4.1 & 7.9 & 7.1 & 1.8 & 0.9 & 46.2 \\
\hline \multicolumn{8}{|l|}{ Male } \\
\hline Number & 80 & 38 & 26 & 24 & 9 & 6 & 183 \\
\hline$\%$ of total & 23.5 & 11.2 & 7.6 & 7.1 & 2.6 & 1.8 & 53.8 \\
\hline \multicolumn{8}{|l|}{ Total } \\
\hline Number & 163 & 52 & 53 & 48 & 15 & 9 & 340 \\
\hline$\%$ of total & 47.9 & 15.3 & 15.6 & 14.1 & 4.4 & 2.6 & 100.0 \\
\hline
\end{tabular}

Note: Scored from 0 (no problem) to 5 (severe problem) 
years for females, with no statistically significant difference between the two sexes (Student's $t$-test $>0.05$ ).

One hundred and one subjects (29.7\%) consumed alcohol (68.3\% male and $31.7 \%$ female). Mean daily alcohol consumption was $2.43(\mathrm{SD} \pm 1.62$ ) units for males and 2.17 ( $\mathrm{SD} \pm 1.32$ ) units for females, and there was no statistically significant difference between the two sexes (Student's $t$-test $>0.05$ ). The most commonly reported alcoholic drinks were wine (30 subjects), followed by beer (21 subjects), and whisky (18 subjects).

One hundred and forty-two (41.8\%) of the participants reported one or more diseases. The reported diseases are presented in Table 5 and belonged to the following categories: cardiovascular, 50 (35.2\%); gastrointestinal, 25 (17.6\%); musculoskeletal, 15 (10.6\%); respiratory, $10(7.0 \%)$; thyroidopathy, 9 (6.3\%); anemia, 3 (2.1\%); and other diseases, 30 (21.1\%).

One hundred and thirty-seven (40.3\%) of the participants reported taking one or more medications for the concomitant diseases. The reported medications were of the following classes: antihypertensive, 43 (31.4\%); anticholesterol, 19 (13.9\%); antiulcerant, 19 (13.9\%); antidiabetic, 11 (8.0\%); antiasthmatic or antichronic obstructive pulmonary disease, 11 (8.0\%); antihypothyroidism, 9 (6.6\%); antiosteoporotics, 7 (5.1\%); and other, 18 (13.1\%).

From 177 subjects with GERD symptoms, 102 or $58.6 \%$ were smokers. Chi-square analysis showed a statistical significant correlation between smoking and GERD symptoms

Table 4 Severity of symptoms (heartburn, chest pain, indigestion, or stomach acid coming up) in patients with gastroesophageal reflux disease

\begin{tabular}{lll}
\hline \multicolumn{2}{l}{ Heartburn, chest pain, indigestion, or stomach acid coming up } \\
\hline Score & Number & $\%$ \\
\hline 1 & 52 & 29.4 \\
2 & 53 & 29.9 \\
3 & 48 & 27.1 \\
4 & 15 & 8.5 \\
5 & 9 & 5.1 \\
Total & 177 & 100 \\
\hline
\end{tabular}

Note: Scored from 0 (no problem) to 5 (severe problem).

Table 5 Concomitant diseases

\begin{tabular}{lll}
\hline Disease & Number & $\%$ \\
\hline Cardiovascular & 50 & 35.2 \\
Gastrointestinal & 25 & 17.6 \\
Musculoskeletal & 15 & 10.6 \\
Respiratory & 10 & 7.0 \\
Thyroidopathy & 9 & 6.3 \\
Anemia & 3 & 2.1 \\
Other & 30 & 21.1 \\
\hline
\end{tabular}

(102 [58.6\%] smokers vs 72 [41.4\%] nonsmokers) ( $P$-value $<0.05)$. According to the logistic regression analysis, the number of smoking cigarettes but not the duration of smoking was found to be related to GERD symptoms. Statistically significant difference was found between male and female smokers and GERD symptoms when demographic characteristics were taken into consideration in the logistic model, indicating that male smokers tend to experience GERD symptoms more often than female smokers.

From 177 subjects with GERD symptoms, 64 or $36.2 \%$ were alcohol drinkers. Chi-square analysis showed a statistically significant correlation between alcohol consumption and GERD symptoms $(P$-value $<0.05)$. Also applying the similar univariate logistic regression analysis as with smoking, the number of daily consumed drinks but not the duration of drinking was found to be related to GERD symptoms.

Statistical analysis did not bring up any correlation between GERD symptoms and concurrent diseases or GERD symptoms and concurrent medication (chi-square tests $>0.05$ ). These results have to be interpreted with skepticism because the aim of the study was not to investigate the correlation between GERD symptoms and concurrent diseases or concurrent medication, and in this regard, the sample size or even the method used was perhaps not appropriate.

\section{Discussion}

GERD is one of the most prevalent gastrointestinal disorders. GERD has an adverse impact on patient's quality of life and also is the most important predisposing factor for Barrett's esophagus and intestinal metaplasia of esophageal mucosa that predisposes to adenocarcinoma of the esophagus. ${ }^{16-20} \mathrm{In}$ addition to the risk of cancer, GERD is well recognized to be associated with some upper respiratory diseases that also contribute adversely to the quality of life. Therefore, there is need for an early diagnosis of GERD to protect patients from the above-mentioned serious complications of GERD.

The prevalence of GERD varies among different geographical areas and among investigators even in the same geographical area. The big difference in the reported GERD prevalence is mainly attributed to the differences in the methods used by each investigator as well as to the absence of a generally adopted definition of GERD.

$\mathrm{pH}$ monitoring with $\mathrm{pH}$ probe is currently the best method for detection of gastroesophageal reflux. However, because $\mathrm{pH}$ electrodes are able to measure only acid reflux, and not measure nonacid reflux episodes, the multichannel intraluminal electrical impedance is considered by many investigators as the gold standard for the diagnosis of GERD. ${ }^{21}$ 
Intraluminal electrical impedance and 24-hour $\mathrm{pH}$ monitoring, being invasive and costly methods, cannot be used for large-scale epidemiological studies. On the other hand, if classic symptoms of heartburn and acid regurgitation dominate a patient's history, these symptoms can be used to establish the diagnosis of GERD with sufficiently high specificity, although sensitivity remains low compared with 24-hour pH monitoring.

In the Montreal definition of GERD, symptoms are the most important component on which GERD diagnosis is based. This is the reason symptom-based questionnaires are used in most epidemiologic studies aiming to assess the prevalence of the disease in the general population.

A large number and a wide variety of questionnaires have been developed for the assessment of GERD, with many differences in characteristics, design, and purposes. The majority of questionnaires are used for the assessment of GERD symptoms with a variety in esophageal and extraesophageal symptoms. Bolier et $\mathrm{al}^{22}$ in a systematic literature review analyzed 65 questionnaires used for assessment of GERD symptoms, response to treatment, diagnosis, and quality of life. He concluded that no one covers all aspects related to GERD and that a suitable questionnaire has to be chosen to satisfy each investigator's specific purposes. ${ }^{22}$

For the purpose of our study, the term "heartburn, chest pain, indigestion, or stomach acid coming up" was used to assess the prevalence of GERD symptoms. We chose the RSI questionnaire as it has not been used, until now, by any other investigator and has not been tested to see if works as GERD diagnostic tool. It is our intention, in a future study, to compare diagnostic validity of RSI questionnaire with other established in clinical practice questionnaires.

In our study, the monthly prevalence of GERD symptoms was found to be $52.0 \%$ in the general Greek population. This prevalence seems to be within the broad range $(26 \%-60 \%)$ of GERD prevalence that has been reported also by other investigators..$^{2-6}$ There were no big differences in the assessment of GERD prevalence between questionnaire and endoscopybased studies. Three population-based, endoscopy studies have been published. The Kalixanda study from Sweden $(n=1,000)^{23}$ in which the prevalence of any troublesome GERD symptom during the past 3 months was $40.0 \%$, the Loiano-Monghidoro study from Italy $(\mathrm{n}=1,033)^{24}$ in which the prevalence of GERD symptoms was $44.3 \%$, and the SILC study from People's Republic of China $(n=1,029)^{25}$ in which the prevalence of GERD symptoms was $4.7 \%$.

The high prevalence of GERD symptoms found in our study could be attributed to the longer period (1 month) set for symptoms reporting by the participants of the study compared to the weekly period that most of the other studies usually use. Another reason could be the inclusion of chest pain and indigestion symptoms in RSI questionnaire. Although these two symptoms are related to GERD, their specificity and sensitivity are much lower compared with heartburn and regurgitation.

No statistically significant difference was found in the prevalence of GERD symptoms as well as in GERD symptoms severity between the two sexes. Reports of the association between GERD symptoms and sex have yielded conflicting results, with some suggesting the prevalence is greater in men, ${ }^{26-28}$ some suggesting it is greater in women, ${ }^{29}$ and others reporting no difference between the sexes. ${ }^{30-32}$

According to our findings, GERD symptoms were reported more frequently in the age group of 65- to 79-yearold participants. In the literature, the association of GERD symptoms with age is not clear as there are conflicting results in published studies. Some reports have suggested that GERD symptoms are associated with age, ${ }^{27-29,32,33}$ but others have suggested no association. ${ }^{30,31}$ Advancing age seems to be associated with the risk of GERD complications.

The severity of GERD symptoms in the majority of patients was found to be mild (59.3\%) or moderate (27.1\%).

No statistically significant difference was found in GERD symptom reporting between urban and rural dwellers. Data regarding association of GERD symptoms and individuals living in urban or rural areas are poor and conflicting. Some investigators have found that individuals living in a rural area had a higher risk of GERD than those living in an urban area, ${ }^{34,35}$ but the reverse has also been found..$^{36}$ Pan et $\mathrm{al}^{37}$ found that GERD was more common in rural than in urban areas in Beijing but that the reverse was true in Shanghai.

In our study, a statistically significant association was found between GERD symptoms and the number of cigarettes smoked daily but not with smoking duration. Smoking has strong evidence to be associated with GERD, as multiple studies have demonstrated a positive association between tobacco smoking and GERD symptoms, , $2,33,38,39$ but, on the other hand, studies of smoking cessation have not demonstrated a benefit on GERD symptoms. ${ }^{40}$

A statistically significant relationship was also found between GERD symptoms and the number of alcoholic drinks consumed daily, but not with the duration of alcohol drinking. Data on the effect of alcohol consumption on GERD symptoms are also conflicting. Alcohol consumption has been inversely associated with GERD symptoms in some studies, ${ }^{32,38,39}$ but physiologic studies indicate that alcohol consumption actually worsens esophageal acid exposure. ${ }^{40}$ 
We must stress that most of the published studies investigated the relationship between GERD symptoms and tobacco smoking or alcoholic drinks consumption to assess the relation as lifestyle habits, and they did not perform further analysis on the daily number of smoking cigarettes or the daily number of alcoholic drinks consumed.

No statistically significant relationship was found between GERD symptoms and concurrent diseases or concomitant medication. The lack of such a relationship in our study can be attributed to the inclusion of a small number of participants with concurrent diseases or concomitant medication. GERD has been associated with respiratory diseases, including asthma, chronic obstructive pulmonary disease, interstitial lung disease, and sleep apnea. ${ }^{41-43}$

The current study has certain limitations, the main one being the lack of RSI validation as a questionnaire for GERD diagnosis. The used diagnostic question regarding "heartburn, chest pain, indigestion, or stomach acid coming up" may be a very simple way to diagnose the existence of GERD; although these symptoms are included almost in all questionnaire-based epidemiological studies related to GERD diagnosis, its specificity and sensitivity have not been tested. It is also well known that "indigestion" cannot be strictly related to GERD and that it is more appropriately associated to functional dyspepsia. Further discussion is necessary to acquire common specifications for GERD diagnostic criteria that would be used in the future for epidemiologic studies to accomplish comparable findings.

Since, in this study, the smokers were also alcohol drinkers, it is not clear whether smoking and alcohol consumption are each a predisposing factor for GERD symptoms, or if the combination of these two factors correlates with GERD. Further studies comparing prevalence of GERD symptoms among nonalcohol drinking tobacco smokers or nonsmoking alcohol drinkers could target this question.

\section{Conclusion}

The prevalence of GERD symptoms based on the participant responses to the question "heartburn, chest pain, indigestion, or stomach acid coming up" was found to be $52.0 \%$ in the general Greek adult population. Sex was found not to be related with the prevalence of GERD symptoms or symptoms severity. GERD symptoms are more frequent in older people. The number of cigarettes smoked daily as well as the number of alcoholic drinks consumed daily was found to be related with GERD symptoms. If we consider that GERD is a risk factor for the development of Barrett's esophagus and esophageal adenocarcinoma, conditions that are increasing in Western populations, the early diagnosis of GERD could contribute in the prevention of such serious diseases.

\section{Disclosure}

The authors report no conflicts of interest in this work.

\section{References}

1. Vakil N, van Zanten SV, Kahrilas P, et al; Global Consensus Group. The Montreal definition and classification of gastroesophageal reflux disease: a global evidence-based consensus. Am J Gastroenterol. 2006;101:1900-1920.

2. Diaz-Rubio M, Moreno-Elola-Olaso C, Rey E, et al. Symptoms of gastro-esophageal reflux: prevalence, severity, duration and associated factors in a Spanish population. Aliment Pharmacol Ther. 2004;19:95-105.

3. Haque M, Wyeth JW, Stace NH, et al. Prevalence, severity and associated features of gastro-oesophageal reflux and dyspepsia: a population-based study. N Z Med J. 2000;113:178-181.

4. Louis E, DeLooze D, Deprez P, et al. Heartburn in Belgium: prevalence, impact on daily life, and utilization of medical resources. Eur J Gastroenterol Hepatol. 2002;14:279-284.

5. Eisen G. The epidemiology of gastroesophageal reflux disease: what we know and what we need to know. Am J Gastroenterol. 2001;96:S16-S18.

6. Jones R, Liker HR, Ducrotté P. Relationship between symptoms, subjective well-being and medication use in gastro-esophageal reflux disease. Int J Clin Pract. 2007;61:1301-1307.

7. El-Serag H, Sweet S, Winchester C, et al. Update on the epidemiology of gastro-oesophageal reflux disease: a systematic review. Gut. 2014;63:871-880.

8. Axon AT. Personal view: to treat or not to treat? Helicobacter pylori and gastro-oesophageal reflux disease - an alternative hypothesis. Aliment Pharmacol Ther. 2004;19:253-261.

9. Papatheodoridis GV, Karamanolis DG. Prevalence and impact of upper and lower gastrointestinal symptoms in the Greek urban general population. Scand J Gastroenterol. 2005;40:412-421.

10. Heidelbaugh J, Van Harrison R, McQuillan M, et al. Gastroesophageal Reflux Disease. UMHS GERD Guideline. Ann Arbor, MI: University of Michigan; 2013. Available from: www.med.umich.edu/1info/FHP/ practiceguides/gerd/gerd.12.pdf. Accessed December 2014.

11. Dent J, Vakil N, Jones R, et al. Accuracy of the diagnosis of GORD by questionnaire, physicians and a trial of proton pump inhibitor treatment: the Diamond Study. Gut. 2010;59:714-721.

12. Kusano M, Shimoyama Y, Sugimoto S, et al. Development and evaluation of FSSG: frequency scale for the symptoms of GERD. $J$ Gastroenterol. 2004;39:888-891.

13. Rubin G, Uebel P, Brimo-Hayek A, et al. Validation of a brief symptom questionnaire (ReQuest in Practice) for patients with gastro-oesophageal reflux disease. Aliment Pharmacol Ther. 2008;27:846-851.

14. Belafsky PC, Postma GN, Koufman JA. Validity and reliability of the reflux symptom index (RSI). J Voice. 2002;16:274-277.

15. Printza A, Kyrgidis A, Oikonomidou E, et al. Assessing laryngopharyngeal reflux symptoms with the reflux symptom index: validation and prevalence in the Greek population. Otolaryngol Head Neck Surg. 2011;145:974-980

16. Lagergren J, Bergstrom R, Lindgren A, et al. Symptomatic gastroesophageal reflux as a risk factor for esophageal adenocarcinoma. N Engl J Med. 1999;340:825-831.

17. Farrow DC, Vaughan TL, Sweeney C, et al. Gastroesophageal reflux disease, use of $\mathrm{H} 2$ receptor antagonists, and risk of esophageal and gastric cancer. Cancer Causes Control. 2000;11:231-238.

18. Wu AH, Tseng CC, Bernstein L. Hiatal hernia, reflux symptoms, body size, and risk of esophageal and gastric adenocarcinoma. Cancer. 2003;98:940-948.

19. Anderson LA, Watson RG, Murphy SJ, et al. Risk factors for Barrett's oesophagus and oesophageal adenocarcinoma: results from the FINBAR study. World J Gastroenterol. 2007;13:1585-1594. 
20. Whiteman DC, Sadeghi S, Pandeya N, et al. Combined effects of obesity, acid reflux and smoking on the risk of adenocarcinomas of the oesophagus. Gut. 2008;57:173-180.

21. Zentilin P, Dulbecco P, Savarino E, et al. Combined multichannel intraluminal impedance and pH-metry: a novel technique to improve detection of gastro-esophageal reflux. Literature review. Dig Liver Dis. 2004;36:565-569.

22. Bolier E, Kessing B, Smout A, Bredenoord A. Systematic review: questionnaires for assessment of gastroesophageal reflux disease. Dis Esophagus. 2015;28:105-120.

23. Ronkainen J, Aro P, Storskrubb T, et al. High prevalence of gastroesophageal reflux symptoms and esophagitis with or without symptoms in the general adult Swedish population: a Kalixanda study report. Scand J Gastroenterol. 2005;40:275-285.

24. Zagari RM, Fuccio L, Wallander MA, et al. Gastro-oesophageal reflux symptoms, oesophagitis and Barrett's oesophagus in the general population: the Loiano-Monghidoro study. Gut. 2008;57:1354-1359.

25. Zou D, He J, Ma X, et al. Epidemiology of symptom-defined gastroesophageal reflux disease and reflux esophagitis: the systematic investigation of gastrointestinal diseases in China (SILC). Scand J Gastroenterol. 2011;46:133-141.

26. Ness-Jensen E, Lindam A, Lagergren J, et al. Changes in prevalence, incidence and spontaneous loss of gastro-oesophageal reflux symptoms a prospective population-based cohort study, the HUNT study. Gut 2012;61:1390-1397.

27. Li YM, Du J, Zhang H, et al. Epidemiological investigation in outpatients with symptomatic gastroesophageal reflux from the Department of Medicine in Zhejiang Province, east China. J Gastroenterol Hepatol. 2008;23:283-289.

28. Wong BC, Kinoshita YI. Systematic review on epidemiology of gastroesophageal reflux disease in Asia. Clin Gastroenterol Hepatol. 2006;4:398-407.

29. Yamagishi H, Koike T, Ohara S, et al. Prevalence of gastroesophageal reflux symptoms in a large unselected general population in Japan. World J Gastroenterol. 2008;14:1358-1364.

30. Locke GR III, Talley NJ, Fett SL, et al. Prevalence and clinical spectrum of gastroesophageal reflux: a population-based study in Olmsted County, Minnesota. Gastroenterology. 1997;112:1448-1456.
31. Nouraie M, Razjouyan H, Assady M, et al. Epidemiology of gastroesophageal reflux symptoms in Tehran, Iran: a population-based telephone survey. Arch Iran Med. 2007;10:289-294.

32. Nocon M, Labenz J, Willich SN. Lifestyle factors and symptoms of gastrooesophageal reflux: a population-based study. Aliment Pharmacol Ther. 2006;23:169-174.

33. El-Serag H, Hill C, Jones R. Systematic review: the epidemiology of gastro-esophageal reflux disease in primary care, using the UK general practice database. Aliment Pharmacol Ther. 2009;29:470-480.

34. He J, Ma X, Zhao Y, et al. A population-based survey of the epidemiology of symptom-defined gastroesophageal reflux disease: the Systematic Investigation of Gastrointestinal Diseases in China. BMC Gastroenterol. 2010;10:94.

35. Wang JH, Luo JY, Dong L, et al. Epidemiology of gastroesophageal reflux disease: a general population-based study in Xi'an of Northwest China. World J Gastroenterol. 2004;10:1647-1651.

36. Shaha M, Perveen I, Alamgir MJ, et al. Prevalence and risk factors for gastro-esophageal reflux disease in the North-Eastern part of Bangladesh. Bangladesh Med Res Counc Bull. 2012;38:108-113.

37. Pan G, Xu G, Ke M, et al. Epidemiological study of symptomatic gastroesophageal reflux disease in China: Beijing and Shanghai. Chin J Dig Dis. 2000;1:2-8.

38. Zheng Z, Nordenstedt H, Pedersen NL, et al. Lifestyle factors and risk for symptomatic gastroesophageal reflux in monozygotic twins. Gastroenterology. 2007;132:87-95.

39. Nilsson M, Johnsen R, Ye W, et al. Lifestyle related risk factors in the aetiology of gastro-oesophageal reflux. Gut. 2004;53:1730-1735.

40. Kaltenbach T, Crockett S, Gerson LB. Are lifestyle measures effective in patients with gastroesophageal reflux disease? An evidence-based approach. Arch Intern Med. 2006;166:965-971.

41. Havemann BD, Henderson CA, El-Serag HB. The association between gastrooesophageal reflux disease and asthma: a systematic review. Gut 2007;56:1654-1664

42. Martinez CH, Han MK. Contribution of the environment and comorbidities to chronic obstructive pulmonary disease phenotypes. Med Clin North Am. 2012;96:713-727.

43. Karkos PD, Leong SC, Benton J, et al. Reflux and sleeping disorders: a systematic review. J Laryngol Otol. 2009;123:372-374.
Clinical and Experimental Gastroenterology

\section{Publish your work in this journal}

Clinical and Experimental Gastroenterology is an international, peerreviewed, open access, online journal publishing original research, reports, editorials, reviews and commentaries on all aspects of gastroenterology in the clinic and laboratory. This journal is included on PubMed. The manuscript management system is completely online

\section{Dovepress}

and includes a very quick and fair peer-review system, which is all easy to use. Visit http://www.dovepress.com/testimonials.php to read real quotes from published authors. 